\title{
The Association Between the Genetic VDR SNP c.907+75C >T and Prostate Cancer Risk Is Modified by Tanning Potential
}

\author{
DESTA A BEYENE ${ }^{1}$, MOHAMMAD R. DAREMIPOURAN $^{1}$, VICTOR APPREY $^{2}$, TAMMEY NAAB $^{3}$, \\ OLAKUNLE O. KASSIM ${ }^{4}$, ROBERT L. COPELAND ${ }^{5}$ and YASMINE M. KANAAN ${ }^{1,4}$ \\ ${ }^{1}$ Cancer Center, Howard University, Washington, DC, U.S.A.; \\ ${ }^{2}$ Community and Family Medicine, College of Medicine, Howard University, Washington, DC, U.S.A.; \\ ${ }^{3}$ Department of Pathology, College of Medicine, Howard University, Washington, DC, U.S.A.; \\ ${ }^{4}$ Department of Microbiology, College of Medicine, Howard University, Washington, DC, U.S.A.; \\ ${ }^{5}$ Department of Pharmacology, College of Medicine, Howard University, Washington, DC, U.S.A.
}

\begin{abstract}
Background: Prostate cancer (PCa) is a multifactorial disease involving complex interactions between genetic and physiologicallenvironmental factors. Vitamin D receptor (VDR) plays a role in numerous cellular pathways and it has been suggested that VDR genetic variants influence individual susceptibility to PCa. Materials and Methods: Logistic regression analysis was used to assess the association of six VDR single nucleotide polymorphisms (SNPS) and factors such as tanning potential and UV sunlight exposure with $\mathrm{PCa}$ risk. Results: Marginal significant interactions were found, with a 2-fold increase risk of PCa between SNP 1 (c.278-69G>A) and sunlight $U V$ exposure [odds ratio $(O R)=2.02,95 \%$ confidence intervaI $(C I)=1.036-4.36 ; p=0.05]$; and a 4-fold increase risk of $P C a$ between SNP $4(c .907+75 C>T)$ and tanning potential ( $O R=4.40,95 \% C I=0.89-29.12 ; p=0.0591)$. In contrast, SNP 5 (rs731236, TaqI) and tanning potential interaction had a protective effect by reducing the risk of $P C a$ by $55 \%$ ( $\beta=-0.804 ; O R=0.448,95 \% C I=0.197-9.42 ; p=0.0427)$. SNPs 2 (rs61614328) and 6 (rs533037428) did not show any association with PCa even in the presence of UV sunlight exposure. Conclusion: The protective effect of SNP 4 from $P C a$ is lost and modified by tanning potential in African
\end{abstract}

This article is freely accessible online.

Correspondence to: Yasmine M. Kanaan, Department of Microbiology, Cancer Center, College of Medicine, Howard University, $520 \mathrm{~W}$ Street, NW, Washington DC, 20059, U.S.A. Tel: +1 2028069540, Fax: +1 2026671686, e-mail: ymkanaan@howard.edu and Robert L. Copeland, Jr., Department of Pharmacology, College of Medicine, Howard University, 520 W St NW, Washington, DC 20059, U.S.A. Tel: +1 2028063861, Fax: +1 2027472721, e-mail: rlcopeland@howard.edu

Key Words: Prostate cancer, vitamin D, vitamin D receptor gene, African American men, single nucleotide polymorphism.
Americans. This finding needs to be verified by larger studies in different ethnic populations.

Prostate cancer (PCa) has high incidence as well as high mortality, which makes it an important worldwide health issue $(1,2)$. Furthermore, PCa etiology is complex, involving many risk factors such as age, vitamin D status, ethnic origin, and family history of $\mathrm{PCa}(3,4)$. Epidemiological studies suggest that $\mathrm{PCa}$ risk may at least partly be determined by interactions between the environment and genetic predisposition (5-7). PCa rates are higher in African American men compared to other ethnic groups in the United States $(4,5,8)$. Additionally, this group of men are more likely to be diagnosed at a later stage of disease development.

PCa risk has been inversely associated with sun exposure. In most individuals, about $90 \%$ of circulating levels of 25 hydroxyvitamin D are derived from casual sun exposure (9). In the United States, high residential sun exposure has been associated with lower mortality rates and reduced risk for $\mathrm{PCa}$ $(10,11)$. A case-control study by Luscombe et al. found a 3fold increased risk with low lifetime sun exposure (12). Vitamin D is an important candidate implicated in PCa risk and its deficiency has been hypothesized to be a risk factor for PCa $(13,14)$. Reduced vitamin D levels correlate with established risk factors such as increasing age, African American ethnicity, and residence in northern latitudes (15). Cordera et al. also used diagnostic serum samples from blood to show that the risk of PCa decreased with higher levels of 1,25-dihydroxyvitamin D (6). The physiological and environmental factors that modify the supply of cutaneous vitamin D are levels of UV exposure, skin pigmentation, and polymorphism in the vitamin D receptor (VDR) gene (16).

$V D R$ polymorphisms have been studied as candidates for PCa susceptibility by many investigators (17-20). The expression or function of $V D R$ may be influenced by polymorphisms in the 3' end. Polymorphisms in VDR might 
alter receptor function and affect PCa susceptibility. More than $60 V D R$ polymorphisms are located in the promoter, in and around exons 2-9, and in the 3'UTR region $(21,22)$. Several genetic studies have reported conflicting results on the associations between VDR polymorphisms and PCa risk (17). The significant effects of $V D R$ polymorphisms and sunlight exposure on $\mathrm{PCa}$ have been reported in our previous study (23). As a follow-up to this, we investigated the specific interactions between individual single nucleotide polymorphisms (SNPs) and other physiological/environmental factors (UV sunlight exposure, tanning potential, vitamin D level) with PCa risk.

\section{Materials and Methods}

Study subjects. Ninety-one African American men with histologically diagnosed adenocarcinoma of the prostate and 92 African American controls were recruited from Howard University Hospital. The Howard University Institutional Review Board (IRB02-MED-42) approved the study protocol, and informed consent was obtained from the study participants. Demographics and medical history details were previously described $(7,24)$. A blood sample was collected prior to treatment from each participant using vacutainers containing EDTA anticoagulant.

Serum 25-hydroxyvitamin D measurement. Enzyme immunoassay from Immunodiagnostic Systems Ltd. (Immunodiagnostic Systems, Fountain Hills, AZ, USA) was used for the quantitative determination of 25-hydroxyvitamin D in serum $(25,26)$.

Polymerase chain reaction (PCR). Genomic DNA extraction was performed using QIAmp DNA Blood Maxi Kit (Qiagen Inc., Valencia, CA, USA) according to the manufacturer's instructions. List of VDR primers and PCR conditions were as previously described by Copeland et al. (27).

Denaturing high-performance liquid chromatography (DHPLC) and $D N A$ sequencing. The entire $V D R$ gene was screened for germline mutations by DHPLC instrument (WAVE ${ }^{\circledR}$ DNA Fragment Analysis System; Transgenomics, Omaha, NE, USA) as previously described (27). Genomic DNA was amplified using GeneAmp 9700 thermal cycler (27) and purified by Qiagen column (QIAquick PCR purification Kit 50; Qiagen, Inc., Valencia, CA, USA). The amplified samples were sequenced using ABI 377 DNA sequencer (Applied Biosystems, Foster City, CA, USA), and fluorescently labeled Bigdye terminator cycle sequencing kit (Applied Biosystems, Foster City, CA, USA). For further confirmation, samples were also sequenced commercially by ACGT Incorporation (Wheeling, IL, USA). Sequencher Version 4.8 software (Gene Codes Corporation, Ann Arbor, MI, USA) was used to analyze the generated data, and SNPs were identified using the International Hapmap project (http//: www.hapmap.org; https://www.ncbi.nlm.nih.gov/projects/SNP/). Nomenclature for the identified SNPs was assigned according to den Dunnen and Antonarakis (28), and the Reference SNP accession ID (rs ID) was assigned for all previously reported SNPs using BLAST SNP (http://www.ncbi.nlm.nih.gov/SNP/snp_blastByOrg.cgi).

Assessment of UVR exposure. Each participant answered questions from the validated UV questionnaire (29). This questionnaire is designed to calculate the total amount of exposure (hours/year) to UV light from childhood until the time of the interview. The cumulative sunlight exposure for each participant was assessed by a combination of his history of occupational and non-occupational sunlight exposure as described previously (24).

Assessment of tanning potential. A computerized narrow-band reflectometer (Mexameter ${ }^{\circledR}$ MX 18, Courage+Khazaka electronic $\mathrm{GmbH}$, Cologne, Germany) was used to measure the skin color (24). The quantitative index of sun exposure (tanning potential) that is related to cumulative lifetime sun exposure was calculated as previously described $(30,31)$.

Statistical analyses. We employed several statistical methods to determine the association of VDR SNPs and factors with PCa. Student's $t$-test and Mann-Whitney were used to determine if there were differences in the mean of age, outdoor UV exposure, serum vitamin $\mathrm{D}$ level, supplemental vitamin D, and dietary vitamin D between PCa cases and controls before and after adjusting for age. Since the $t$-test showed age to be a significant factor, logistic regression analysis was carried out on the other factors by adjusting for age.

Furthermore, logistic regression was used to select the best predictors among the detected SNPs and their interactions with the physiological/environmental factors. The physiological/environmental variables were standardized for logistic regression in determining the effect of the interaction between the SNPs, factors, and PCa. The association of SNPs, UV sunlight exposure, and tanning potential with PCa risk were demonstrated using interaction plots.

Odds ratios (OR) and 95\% confidence intervals (CI) were calculated, adjusting for age. Estimates were considered statistically significant for two-tailed values of $p<0.05$. All analyses were carried out using SPSS version 26.0 (IBM, Armonk, NY, USA).

\section{Results}

Previously, we conducted a case-control study to investigate the association of vitamin D, UV sunlight exposure, and tanning potential with $\mathrm{PCa}$. At the same time, we screened the $V D R$ gene for mutations/SNPs. We identified seven distinct polymorphisms [SNP 1 (c.278-69G>A), SNP 2 (rs61614328), SNP 3 (rs11574114), SNP 4 (c.907+75 C>T), SNP 5 (rs731236, TaqI), SNP 6 (rs533037428), and SNP 7 (rs7975232, ApaI)] (23). However, SNP 3 was detected in only one case, therefore, this SNP was excluded from this study. In this article, we further investigated the genephysiological/environmental interaction relating to PCa risk.

Before age-matching, Mann-Whitney test and Student's $t$ test showed significant differences between the cases and controls for age and outdoor sunlight exposure $(p=0.001)$, while being marginally significant for supplemental vitamin D intake $(p=0.079)$. Men 60 years and older were found to have a higher incidence of PCa compared to those younger than 50 years, and the mean UV sunlight exposure was higher in controls $(5,017.2 \mathrm{~h})$ than in cases $(1,786.6 \mathrm{~h})$. The mean serum vitamin D levels for cases $(26.8 \mathrm{ng} / \mathrm{ml})$ and controls $(29.1 \mathrm{ng} / \mathrm{ml})$ were both below the normal range $(30-74 \mathrm{ng} / \mathrm{ml})$ (Table I). To ensure the difference in mean of outdoor UV sun 
Beyene et al: Gene-Environmental Interaction and Prostate Cancer Risk

Table I. The mean values for physiological/environmental factors in unmatched cases and controls $(N=182)$.

\begin{tabular}{lrrrrrr}
\hline \multirow{2}{*}{ Characteristic } & \multicolumn{2}{c}{ Cases } & \multicolumn{2}{c}{ Controls } & \multicolumn{2}{c}{$p$-Value } \\
\cline { 2 - 7 } & Mean & Standard error & Mean & Standard error & Student's $t$-test & Mann-Whitney \\
\hline Age, years & 64.53 & 0.940 & 58.67 & 0.991 & $\mathbf{0 . 0 0 1}$ & $\mathbf{0 . 0 0 0 1}$ \\
UV sunlight exposure, h & 1786.57 & 227.828 & 5017.18 & 857.055 & $\mathbf{0 . 0 0 1}$ & $\mathbf{0 . 0 0 0 7}$ \\
Serum vitamin D, ng/ml & 26.75 & 1.612 & 29.06 & 1.475 & 0.291 & 0.2079 \\
Supplemental vitamin D, mg/day & 129.70 & 20.637 & 169.51 & 20.427 & 0.174 & 0.0791 \\
Dietary vitamin D, mg/day & 140.32 & 11.978 & 155.00 & 13.838 & 0.42 & 0.4157 \\
Tanning potential, \% & 30.32 & 2.658 & 36.51 & 3.4813 & 0.16 & 0.3982 \\
\hline
\end{tabular}

Statistically significant $p$-values are shown in bold.

Table II. The mean values for physiological/environmental factors in age-matched cases and controls $(N=106)$.

\begin{tabular}{lrrrrrr}
\hline Characteristic & \multicolumn{2}{c}{ Cases } & \multicolumn{2}{c}{ Controls } & & $p$-Value \\
\cline { 2 - 7 } & Mean & Standard error & Mean & Standard error & Student's $t$-test & Mann-Whitney \\
\hline Age, years & 60.9 & 1.146 & 60.9 & 1.1460 & 0.990 & 0.997 \\
UV sunlight exposure, $\mathrm{h}$ & 1846.98 & 373.131 & 6117.44 & 1360.832 & $\mathbf{0 . 0 0 3}$ & $\mathbf{0 . 0 4 4}$ \\
Serum vitamin D, ng/ml & 28.27 & 2.138 & 29.72 & 1.918 & 0.618 & 0.7 \\
Supplemental vitamin D, mg/day & 147.25 & 27.889 & 171.99 & 25.367 & 0.516 & 3.16 \\
Dietary vitamin D, mg/day & 156.67 & 17.538 & 146.06 & 20.538 & 0.689 & 0.857 \\
Tanning potential, \% & 24.77 & 3.069 & 39.5 & 4.699 & $\mathbf{0 . 0 1 0}$ & $\mathbf{0 . 0 2 6}$ \\
\hline
\end{tabular}

Statistically significant $p$-values are shown in bold.

Table III. Association of age, UV sunlight exposure, vitamin D levels, and prostate cancer risk using logistic regression.

\begin{tabular}{|c|c|c|c|c|c|}
\hline Variable & $\beta$ & Standard error & Odds ratio $^{\mathrm{a}}$ & $95 \% \mathrm{CI}$ & $p$-Value \\
\hline Intercept & -1.5252 & 0.6051 & & & 0.011 \\
\hline \multicolumn{6}{|l|}{ Age, years } \\
\hline $40-49$ & & & 1 & & (Ref) \\
\hline $50-59$ & 0.697 & 0.678 & 2.008 & $0.531-7.592$ & 0.304 \\
\hline $60-69$ & 2.211 & 0.676 & 9.126 & $2.422-34.382$ & 0.001 \\
\hline$\geq 70$ & 2.167 & 0.714 & 8.734 & $2.154-35.416$ & 0.002 \\
\hline UV sunlight exposure ${ }^{b}$ & -1.170 & 0.373 & 0.310 & $0.149-0.645$ & 0.001 \\
\hline Serum vitamin $\mathrm{D}^{\mathrm{b}}$ & -0.093 & 0.177 & 0.911 & $0.643-1.289$ & 0.598 \\
\hline Supplemental vitamin $\mathrm{D}^{\mathrm{b}}$ & -0.050 & 0.180 & 0.950 & $0.667-1.355$ & 0.778 \\
\hline Dietary vitamin $\mathrm{D}^{\mathrm{b}}$ & 0.091 & 0.196 & 1.096 & $0.746-1.609$ & 0.640 \\
\hline Tanning potential ${ }^{b}$ & -0.346 & 0.186 & 0.707 & $0.491-1.018$ & 0.062 \\
\hline
\end{tabular}

aAdjusted for age. ${ }^{b}$ Variables are standardized. Statistically significant $p$-values are shown in bold.

exposure was not influenced by imbalances in ages of controls and cases, we reanalyzed the data in pairs of men matched for age. Significant differences were found only for UV sunlight exposure $(p=0.003)$ and tanning potential $(p=0.01)$ (Table II). Furthermore, significant associations were found between $\mathrm{PCa}$ risk and age older than 60 years as well as tanning potential $(p=0.06)$ and outdoor UV sun exposure $(p=0.001)$ (Table III).
The interactions between the individual VDR SNPs and factors for PCa risk were analyzed using logistic regression (Tables IV, V, and VI). VDR SNPs 4 and 5 showed a significant protective effect by reducing PCa risk $(\beta=-3.23, \mathrm{OR}=0.039$, $95 \% \mathrm{CI}=0.0005-0.274, p=0.01670$; and $\beta=-1.884$, $\mathrm{OR}=0.152$, $95 \% \mathrm{CI}=0.075-0.295, p=6.05 \times 10^{-8}$, respectively). Notable interactions with a 2-fold increase risk of PCa between SNP 1 
Table IV. Assessment of the most predictive vitamin D receptor (VDR) single nucleotide polymorphism (SNP) 1 (c.278-69G>A) interaction with outdoor UV sunlight exposure concerning prostate cancer risk using logistic regression analysis.

\begin{tabular}{lccccc}
\hline Variable & $\beta$ & Standard error & Odds ratio & 95\% CI & $p$-Value \\
\hline Intercept & -0.98 & 0.193 & 0.907 & $0.619-1.32$ & 0.612 \\
VDR SNP 1 & 0.237 & 0.311 & 1.27 & $0.690-2.34$ & 0.446 \\
UV sunlight exposure & -0.48 & 0.279 & 0.619 & $0.348-1.049$ & 0.0850 \\
VDR SNP 1 $\times$ sunlight & 0.702 & 0.361 & 2.02 & $1.036-4.361$ & 0.0520 \\
\hline
\end{tabular}

Table V. Assessment of the most predictive vitamin D receptor (VDR) single nucleotide polymorphism (SNP) 4 (c.907+75C>T) interaction with tanning potential (TP) concerning prostate cancer risk using logistic regression analysis.

\begin{tabular}{lccccc}
\hline Variable & $\beta$ & Standard error & Odds ratio & 95\% CI & $p$-Value \\
\hline Intercept & 0.277 & 0.185 & 1.319 & $0.919-1.905$ & 0.135 \\
VDR SNP 4 & -3.23 & 1.354 & 0.039 & $0.0005-0.274$ & $\mathbf{0 . 0 1 6 7}$ \\
TP & -0.54 & 0.203 & 0.584 & $0.385-0.855$ & $\mathbf{0 . 0 0 7 8 5}$ \\
VDR SNP 5 $\times$ TP & 1.482 & 0.785 & 4.40 & $0.891-29.12$ & 0.0591 \\
\hline
\end{tabular}

Statistically significant $p$-values are shown in bold.

Table VI. Assessment of the most predictive vitamin D receptor (VDR) single nucleotide polymorphism (SNP) 5 (rs 731236$)$ interaction with tanning potential (TP) concerning prostate cancer risk using logistic regression analysis.

\begin{tabular}{|c|c|c|c|c|c|}
\hline Variable & $\beta$ & Standard error & Odds ratio & $95 \% \mathrm{CI}$ & $p$-Value \\
\hline Intercept & 1.082 & 0.260 & 2.95 & $1.816-5.062$ & $2.964 \times 10^{-5}$ \\
\hline VDR SNP 5 & -1.884 & 0.348 & 0.152 & $0.0750-0.295$ & $6.05 \times 10^{-8}$ \\
\hline TP & 0.381 & 0.314 & 1.463 & $0.817-2.848$ & 0.2256 \\
\hline VDR SNP $5 \times$ TP & -0.804 & 0.397 & 0.448 & $0.197-0.942$ & 0.0427 \\
\hline
\end{tabular}

Statistically significant $p$-values are shown in bold.

and sunlight $\mathrm{UV}$ exposure $(\mathrm{OR}=2.02,95 \% \mathrm{CI}=1.036-4.36$; $p=0.052$ ); and a 4 -fold increase risk of PCa between SNP 4 and tanning potential $(\mathrm{OR}=4.40,95 \% \quad \mathrm{CI}=0.89-29.12$; $p=0.0591 \times 10^{-2}$ ) were found. In contrast, potential interaction between SNP 5 and tanning had a protective effect by reducing the risk of $\mathrm{PCa}$ by $55 \%(\beta=-0.804$; OR=0.448, 95\% $\mathrm{CI}=0.197$ 9.42; $p=0.0427)$. SNPs 2 and 6 did not show any association with PCa even in the presence of UV sunlight exposure. Furthermore, the significant interactions of the SNPs, UV sunlight exposure, tanning potential with PCa risk were also demonstrated using the interaction plot (Figures 1-3). An increased risk of PCa was found with increase of UV sunlight exposure and in the presence of SNP 1.

\section{Discussion}

Most of the emerging epidemiological evidence has shown that $V D R$ polymorphisms and vitamin $\mathrm{D}$ from sunlight exposure play a role in the development of PCa. Liu et al. reported the association of six variants with $\mathrm{PCa}$ and their cumulative effect (32). This relationship suggested that men who carried any combination of 1,2, or $>3$ risky genotypes had a gradually increased PCa risk. However, Berndt et al. did not find evidence to support an association between any of the VDR polymorphisms and the risk of PCa (33). We recently reported that $V D R$ SNPs $4(\mathrm{c} 907+75 \mathrm{C}>\mathrm{T})$ and 7 (rs7975232) play a significant role in the development of $\mathrm{PCa}$ in African Americans (7, 23).

The cumulative effects of VDR polymorphism, UV sunlight exposure, and vitamin D level on PCa risk has also been investigated by other researchers $(34,35)$. North American-based studies linking latitude with PCa mortality have shown that UV radiation (UVR) has a protective effect against the development of PCa $(11,34)$ and suggested that the impact of $V D R$ genotype might be evident in men with certain levels of UVR exposure. Bodiwala et al. used a median value of cumulative UVR exposure per year $(1,100$ $\mathrm{h}$ /year) and found no association below the median, while 


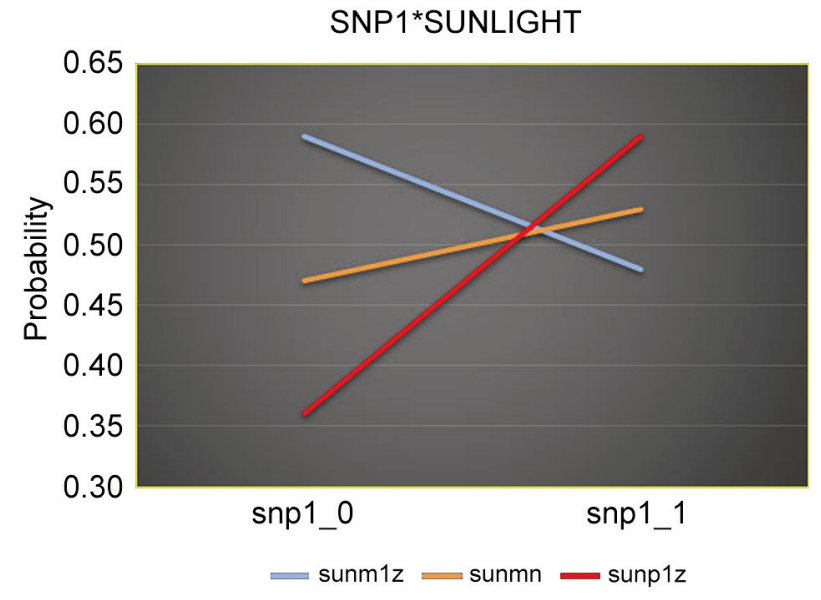

Figure 1. Demonstration of the most predictive vitamin $D$ receptor (VDR) single nucleotide polymorphism (SNP) 1 (c.278-69G>A) interaction with $U V$ sunlight exposure concerning prostate cancer risk using the interaction plot.

$V D R$ polymorphisms were associated with $\mathrm{PCa}$ risk in men with UVR exposure levels above the median (19). In our study, the mean sunlight UV exposure levels for the cases $(1,787 \mathrm{~h} /$ year $)$ and the controls $(5,017 \mathrm{~h} /$ year $)$ were much higher than that reported by Bodiwala et al. (19). The mean UV sunlight exposure for the controls was almost three times that of the cases, indicating the protective effect of UV sunlight exposure against PCa. This is reflected by the negative regression coefficient $(\beta=-1.1704)$ between $U V$ sunlight exposure and PCa. Bodiwala et al. (16) and Luscombe et al. (12) showed that the pathogenesis of $\mathrm{PCa}$ in men with low levels of UVR exposure is different from that in men with higher levels. Thus, VDR variants are not associated with PCa risk in the group with a relatively low UVR exposure. Levels of UVR exposure below the median may be associated with PCa that develops because of relative vitamin D deficiency, which appears to have been the case in the present study (levels below $30 \mathrm{ng} / \mathrm{ml}$ ).

Conflicting results have been reported on the effect of the vitamin D level on PCa risk. Recent studies by Park et al. (30) and Kristal et al. (36) did not find any association of vitamin D uptake with PCa risk. Huncharek et al. found no significant association in a meta-analysis in observational studies regarding diet, calcium, and vitamin $\mathrm{D}$ intake and the risk of PCa (37). On the other hand, Bahar et al. showed that plasma vitamin $\mathrm{D}<26 \mathrm{ng} / \mathrm{ml}$ was associated with a threefold risk for PCa (38). A study by Murphy et al. showed that vitamin D deficiency was associated with higher Gleason score and tumor stage in both Caucasians and African Americans (39). This means that vitamin D deficiency may play a role in influencing the relationship between UV sunlight exposure and PCa risk. Nevertheless, the inverse relationship between UV sunlight

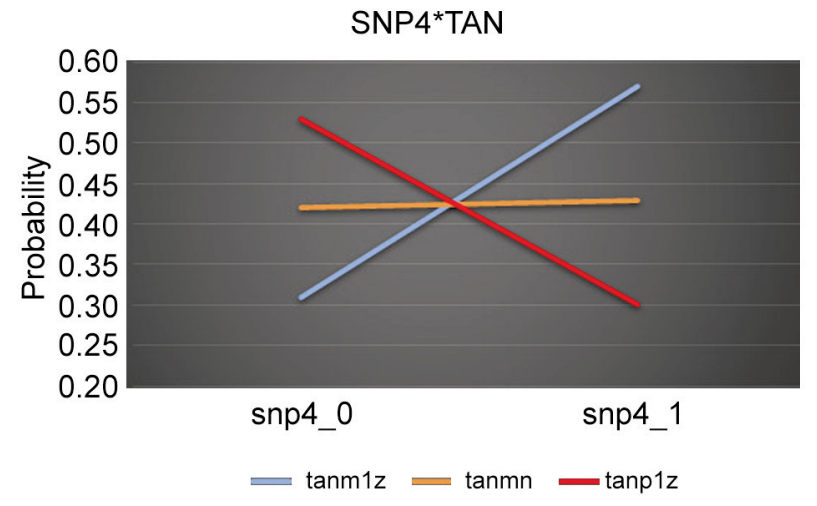

Figure 2. Demonstration of the most predictive vitamin $D$ receptor (VDR) single nucleotide polymorphism (SNP) 4 (c.907+75C>T) interaction with tanning potential concerning prostate cancer risk using interaction plot.

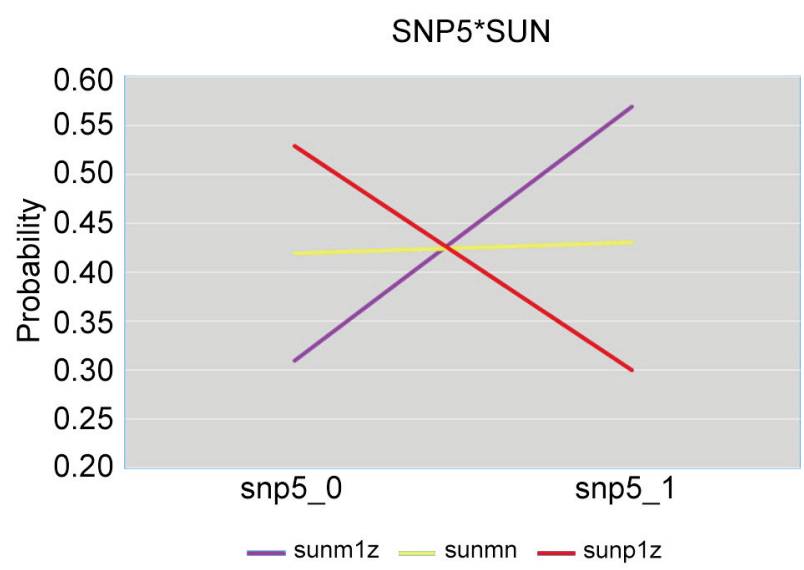

Figure 3. Demonstration of the most predictive vitamin $D$ receptor $(V D R)$ single nucleotide polymorphism (SNP) 5 (rs731236) interaction with UV sunlight exposure concerning prostate cancer risk using the interaction plot.

exposure and PCa risk has been reported by Liu et al. (32). In the United States, high levels of UV sun exposure were associated with lower mortality rates and reduced risk of PCa (34). Moreover, a case-control study from England revealed a 3 -fold increased risk to be associated with a low lifetime UV sunlight exposure (12). Results from our previous studies (23, 24) have shown that outdoor UV sunlight exposure was associated with reduced PCa risk.

\section{Conclusion}

This study showed that the association of VDR SNPs with PCa risk may be dependent on the level of UV sunlight exposure 
and the level of serum vitamin D. VDR variants are not associated with PCa risk in men with relatively low UV sunlight exposure and high serum vitamin D level. As sunlight exposure increases, the risk of PCa decreases, which indicates an inverse relationship between the two. Similarly, the risk of $\mathrm{PCa}$ decreases with a diminution in tanning potential. Results from this study also showed that UV sunlight exposure has a protective effect against PCa when the vitamin D level is not limiting. Overall, these findings provide additional information for future epidemiological and functional studies in African Americans. The generated data of gene-physiological/ environmental factors interaction from this study is important for discovery of novel genetic risk factors, risk prediction, and identification of certain high-risk populations to outline public health strategies for targeted prevention.

\section{Conflicts of Interest}

Authors have no personal or financial conflicts of interest to report.

\section{Authors' Contributions}

DB and MD conducted the laboratory analyses, and writing-original draft preparation. VA performed the statistical analyses. TN collected the clinical data and contributed to data analyses. OOK contributed to the data analyses and article writing-reviewing and editing. RLC and YK were responsible for the experimental design and contributed to the data analyses and article writing.

\section{Acknowledgements}

This work was supported by US Army Medical Research and Materiel Command (USAMRMC) [DAMD17-03-1-0069].

\section{References}

1 Wong MC, Goggins WB, Wang HH, Fung FD, Leung C, Wong SY, Ng CF and Sung JJ: Global incidence and mortality for prostate cancer: Analysis of temporal patterns and trends in 36 countries. Eur Urol 70(5): 862-874, 2016. PMID: 27289567. DOI: $10.1016 /$ j.eururo.2016.05.043

2 Haas GP, Delongchamps N, Brawley OW, Wang CY and de la Roza G: The worldwide epidemiology of prostate cancer: Perspectives from autopsy studies. Can J Urol 15(1): 3866-3871, 2008. PMID: 18304396.

3 Schuurman AG, Zeegers MP, Goldbohm RA and van den Brandt PA: A case-cohort study on prostate cancer risk in relation to family history of prostate cancer. Epidemiology 10(2): 192-195, 1999. PMID: 10069259.

4 Ekman P, Pan Y, Li C and Dich J: Environmental and genetic factors: A possible link with prostate cancer. Br J Urol 79 Suppl 2: 35-41, 1997. PMID: 9126068. DOI: 10.1111/j.1464410x.1997.tb16919.x

5 Gupta D, Lammersfeld CA, Trukova K and Lis CG: Vitamin D and prostate cancer risk: A review of the epidemiological literature. Prostate Cancer Prostatic Dis 12(3): 215-226, 2009. PMID: 19350051. DOI: 10.1038/pcan.2009.7
6 Corder EH, Guess HA, Hulka BS, Friedman GD, Sadler M, Vollmer RT, Lobaugh B, Drezner MK, Vogelman JH and Orentreich N: Vitamin D and prostate cancer: A prediagnostic study with stored sera. Cancer Epidemiol Biomarkers Prev 2(5): 467-472, 1993. PMID: 8220092.

7 Kanaan YM, Beyene D, Daremipouran D, Mireku-Boateng A, Williams R, Jackson A, Bonney G, Apprey V, Danie 1MG, Wutoh AK, Rohan J, Ricks-Santi L and Copeland JR: Association of cumulative ultraviolet radiation exposure with prostate cancer risk in a case-control study of African-American men. The Open Prostate Cancer J 5: 1876-8229, 2012. PMID: 25398820. DOI: $10.2174 / 1876822901205010008$

8 Parkin DM, Pisani P and Ferlay J: Estimates of the worldwide incidence of 25 major cancers in 1990. Int J Cancer 80(6): 827841, 1999. PMID: 10074914. DOI: 10.1002/(sici) 10970215(19990315)80:6<827::aid-ijc6>3.0.co;2-p

9 Holick MF: Vitamin d: A millenium perspective. J Cell Biochem 88(2): 296-307, 2003. PMID: 12520530. DOI: 10.1002/jcb.10338

10 Schwartz GG and Hulka BS: Is vitamin d deficiency a risk factor for prostate cancer? (hypothesis). Anticancer Res 10(5A): 13071311, 1990. PMID: 2241107.

11 Hanchette CL and Schwartz GG: Geographic patterns of prostate cancer mortality. Evidence for a protective effect of ultraviolet radiation. Cancer 70(12): 2861-2869, 1992. PMID: 1451068. DOI: $10.1002 / 1097-0142(19921215) 70: 12<2861:$ :aid cncr2820701224>3.0.co;2-g

12 Luscombe CJ, Fryer AA, French ME, Liu S, Saxby MF, Jones PW and Strange RC: Exposure to ultraviolet radiation: Association with susceptibility and age at presentation with prostate cancer. Lancet 358(9282): 641-642, 2001. PMID: 11530156. DOI: 10.1016/S0140-6736(01)05788-9

13 Bouillon R, Eelen G, Verlinden L, Mathieu C, Carmeliet G and Verstuyf A: Vitamin d and cancer. J Steroid Biochem Mol Biol 102(1-5): 156-162, 2006. PMID: 17113979. DOI: 10.1016/ j.jsbmb.2006.09.014

14 Giovannucci E: The epidemiology of vitamin D and cancer incidence and mortality: A review (United States). Cancer Causes Control 16(2): 83-95, 2005. PMID: 15868450. DOI: 10.1007/s10552-004-1661-4

15 Schwartz GG: Vitamin D and the epidemiology of prostate cancer. Semin Dial 18(4): 276-289, 2005. PMID: 16076349. DOI: $10.1111 / \mathrm{j} .1525-139 X .2005 .18403 . \mathrm{x}$

16 Bodiwala D, Luscombe CJ, French ME, Liu S, Saxby MF, Jones PW, Ramachandran S, Fryer AA and Strange RC: Susceptibility to prostate cancer: Studies on interactions between UVR exposure and skin type. Carcinogenesis 24(4): 711-717, 2003. PMID: 12727800. DOI: 10.1093/carcin/bgg021

17 Blazer DG, 3rd, Umbach DM, Bostick RM and Taylor JA: Vitamin D receptor polymorphisms and prostate cancer. Mol Carcinog 27(1): 18-23, 2000. PMID: 10642433. DOI: 10.1002/(sici)1098-2744(200001)27:1<18::aid-mc4>3.3.co;2-f

18 Gsur A, Madersbacher S, Haidinger G, Schatzl G, Marberger M, Vutuc $\mathrm{C}$ and Micksche M: Vitamin D receptor gene polymorphism and prostate cancer risk. Prostate 51(1): 30-34, 2002. PMID: 11920955. DOI: 10.1002/pros.10064

19 Bodiwala D, Luscombe CJ, French ME, Liu S, Saxby MF, Jones PW, Fryer AA and Strange RC: Polymorphisms in the vitamin $\mathrm{D}$ receptor gene, ultraviolet radiation, and susceptibility to prostate cancer. Environ Mol Mutagen 43(2): 121-127, 2004. PMID: 14991752. DOI: $10.1002 / \mathrm{em} .20000$ 
20 Uitterlinden AG, Fang Y, Van Meurs JB, Pols HA and Van Leeuwen JP: Genetics and biology of vitamin D receptor polymorphisms. Gene 338(2): 143-156, 2004.PMID: 15315818. DOI: $10.1016 /$ j.gene.2004.05.014

21 Fang Y, van Meurs JB, d'Alesio A, Jhamai M, Zhao H, Rivadeneira F, Hofman A, van Leeuwen JP, Jehan F, Pols HA and Uitterlinden AG: Promoter and 3'-untranslated-region haplotypes in the vitamin $\mathrm{D}$ receptor gene predispose to osteoporotic fracture: The Rotterdam study. Am J Hum Genet 77(5): 807-823, 2005. PMID: 16252240. DOI: 10.1086/497438

22 Kostner K, Denzer N, Muller CS, Klein R, Tilgen W and Reichrath J: The relevance of vitamin D receptor (VDR) gene polymorphisms for cancer: A review of the literature. Anticancer Res 29(9): 3511-3536, 2009. PMID: 19667145.

23 Daremipouran MR, Beyene D, Apprey V, Naab TJ, Kassim OO, Copeland RL, Jr. and Kanaan YM: The association of a novel identified VDR SNP with prostate cancer in African American men. Cancer Genomics Proteomics 16(4): 245-255, 2019. PMID: 31243105 . DOI: $10.21873 / \mathrm{cgp} .20129$

24 Beyene D, Daremipouran M, Apprey V, Williams R, Ricks-Santi L, Kassim OO, Naab TJ, Kanaan YM and Copeland RL, Jr.: Use of tanning potential as a predictor for prostate cancer risk in African-American men. In Vivo 28(6): 1181-1187, 2014. PMID: 25398820

25 Ruohola JP, Laaksi I, Ylikomi T, Haataja R, Mattila VM, Sahi T, Tuohimaa P and Pihlajamaki H: Association between serum 25(OH)D concentrations and bone stress fractures in Finnish young men. J Bone Miner Res 21(9): 1483-1488, 2006. PMID: 16939407. DOI: 10.1359/jbmr.060607

26 Carter CJ: The fox and the rabbits-environmental variables and population genetics (1) replication problems in association studies and the untapped power of GWAS (2) vitamin A deficiency, Herpes simplex reactivation and other causes of Alzheimer's disease. ISRN Neurol 2011: 394678, 2011. PMID: 22389816. DOI: $10.5402 / 2011 / 394678$

27 Copeland RL, Beyene D, Apprey V, Daremipouran MR, Naab TJ, Kassim OO and Kanaan YM: Dhplc elution patterns of VDR PCR products can predict prostate cancer susceptibility in African American men. Cancer Genomics Proteomics 14(6): 461-467, 2017. PMID: 29109096. DOI: $10.21873 / \mathrm{cgp} .20056$

28 den Dunnen JT and Antonarakis SE: Mutation nomenclature extensions and suggestions to describe complex mutations: A discussion. Hum Mutat 15(1): 7-12, 2000. PMID: 10612815. DOI: $10.1002 /($ S ICI) $1098-1004(200001) 15: 1<7:$ :AID HUMU4>3.0.CO;2-N

29 McCarty CA: Sunlight exposure assessment: Can we accurately assess vitamin D exposure from sunlight questionnaires? Am J Clin Nutr 87(4): 1097s-1101s, 2008. PMID: 18400741. DOI: 10.1093/ajen/87.4.1097S

30 Park SY, Murphy SP, Wilkens LR, Stram DO, Henderson BE and Kolonel LN: Calcium, vitamin D, and dairy product intake and prostate cancer risk: The multiethnic cohort study. Am J Epidemiol 166(11): 1259-1269, 2007. PMID: 17925283. DOI: 10.1093/aje/kwm269
31 Westerhof W, Estevez-Uscanga O, Meens J, Kammeyer A, Durocq $\mathrm{M}$ and Cario I: The relation between constitutional skin color and photosensitivity estimated from UV-induced erythema and pigmentation dose-response curves. J Invest Dermatol 94(6): 812-816, 1990. PMID: 2355184. DOI: 10.1111/15231747.ep12874671

32 Liu M, Shi X, Yang F, Wang J, Xu Y, Wei D, Yang K, Zhang Y, Wang X, Liang S, Chen X, Sun L, Zhu X, Zhao C, Zhu L, Tang $\mathrm{L}$, Zheng $\mathrm{C}$ and Yang Z: The cumulative effect of gene-gene and gene-environment interactions on the risk of prostate cancer in chinese men. Int J Environ Res Public Health 13(2): 162, 2016. PMID: 26828504. DOI: 10.3390/ijerph13020162

33 Berndt SI, Dodson JL, Huang WY and Nicodemus KK: A systematic review of vitamin D receptor gene polymorphisms and prostate cancer risk. J Urol 175(5): 1613-1623, 2006. PMID: 16600714. DOI: 10.1016/S0022-5347(05)00958-4

34 Ingles SA, Coetzee GA, Ross RK, Henderson BE, Kolonel LN, Crocitto L, Wang W and Haile RW: Association of prostate cancer with vitamin D receptor haplotypes in African-Americans. Cancer Res 58(8): 1620-1623, 1998. PMID: 9563471.

35 Rukin NJ, Luscombe CJ and Strange RC: Re: A systematic review of vitamin $\mathrm{D}$ receptor gene polymorphisms and prostate cancer risk. J Urol 175: 1613-1623, 2006 PMID: 17162099. DOI: $10.1016 /$ j.juro.2006.08.086

36 Kristal AR, Arnold KB, Neuhouser ML, Goodman P, Platz EA, Albanes D and Thompson IM: Diet, supplement use, and prostate cancer risk: Results from the prostate cancer prevention trial. Am J Epidemiol 172(5): 566-577, 2010. PMID: 20693267. DOI: $10.1093 / \mathrm{aje} / \mathrm{kwq} 148$

37 Huncharek M, Muscat J and Kupelnick B: Dairy products, dietary calcium and vitamin D intake as risk factors for prostate cancer: A meta-analysis of 26,769 cases from 45 observational studies. Nutr Cancer 60(4): 421-441, 2008. PMID: 18584476. DOI: $10.1080 / 01635580801911779$

38 Mikhak B, Hunter DJ, Spiegelman D, Platz EA, Hollis BW and Giovannucci E: Vitamin D receptor (VDR) gene polymorphisms and haplotypes, interactions with plasma 25-hydroxyvitamin D and 1,25-dihydroxyvitamin D, and prostate cancer risk. Prostate 67(9): 911-923, 2007. PMID: 17440943. DOI: 10.1002/pros.20570

39 Murphy AB, Nyame Y, Martin IK, Catalona WJ, Hollowell CM, Nadler RB, Kozlowski JM, Perry KT, Kajdacsy-Balla A and Kittles R: Vitamin D deficiency predicts prostate biopsy outcomes. Clin Cancer Res 20(9): 2289-2299, 2014. PMID: 24789033. DOI: $10.1158 / 1078-0432 . C C R-13-3085$

Received July 27, 2020

Revised September 10, 2020

Accepted September 14, 2020 